\title{
Abolición gradual y libertades vigiladas en el Río de la Plata. La política de control de libertos de
}

\section{3}

Gradual abolition and supervised freedom in the Rio de la Plata. The freedmen control policy (1813)

\section{Magdalena Candioti}

\section{OpenEdition}

\section{Journals}

Electronic version

URL: http://journals.openedition.org/corpusarchivos/1567

DOI: $10.4000 /$ corpusarchivos. 1567

ISSN: $1853-8037$

\section{Publisher}

Diego Escolar

\section{Electronic reference}

Magdalena Candioti, « Abolición gradual y libertades vigiladas en el Río de la Plata. La política de control de libertos de 1813 », Corpus [En línea], Vol 6, No 1 | 2016, Publicado el 01 julio 2016, consultado el 19 abril 2019. URL : http://journals.openedition.org/corpusarchivos/1567 ; DOI : 10.4000/corpusarchivos. 1567

This text was automatically generated on 19 April 2019. 


\section{Abolición gradual y libertades vigiladas en el Río de la Plata. La política de control de libertos de 1813}

Gradual abolition and supervised freedom in the Rio de la Plata. The freedmen control policy (1813)

Magdalena Candioti

\section{Reglamento para educación y ejercicio de los libertos: localización e interés}

1 El Reglamento para educación y ejercicio de los libertos fue dictado por la General Constituyente de las Provincias Unidas del Río de la Plata que se reunió desde el 31 de enero de 1813 con el objetivo de acordar una constitución para el desmembrado territorio del antiguo virreinato. La intención de "constitucionalizar" no se concretó dadas las fuertes disidencias internas pero muchas de las disposiciones adoptadas por el Congreso continuaron vigentes en las distintas jurisdicciones que intentaron conformar esa unidad. Una de estas leyes fue la que estableció "la libertad de los hijos de las esclavas" y el reglamento en cuestión.

2 Las actas de la Asamblea no se conservan por lo que sólo disponemos de copias de sus provisiones que fueron circuladas de modo manuscrito a las autoridades y publicadas en la Gaceta de Buenos Aires para conocimiento del público.

3 El Reglamento para educación y ejercicio de los libertos, particularmente, se divulgó en el número 48 de la Gaceta, el día miércoles 10 de marzo de 1813. Luego fue integrado en distintas compilaciones de leyes entre las que se destaca el Registro oficial de leyes de la República Argentina (1879).

El documento reviste interés por diversas razones. En primer lugar, ilustra con claridad el carácter condicional, especial y limitado de la libertad imaginada para los hijos de las 
esclavas en el Río de la Plata. En segundo lugar, contribuye a periodizar los modos de construcción de "otros" étnicos y ponderar el peso de la esclavitud como estigma de larga duración. Finalmente, permite desmostar el mito de una esclavitud benigna y una abolición temprana y no conflictiva resaltando la centralidad de la figura del liberto. Esta categoría reactualizada por los legisladores rioplatenses fue central para limitar la autonomía y los derechos de miles de afrodescendientes hasta la abolición total. El Reglamento constituyó así un instrumento clave que permitió a las élites decidir sobre, y controlar, la vida de los emancipados haciéndolos vulnerables frente a los requerimientos de los patronos y el estado.

5 Los trabajos sobre este documento y sus usos se realizan en el marco de una investigación comparada sobre esclavitud y abolición en Buenos Aires y Santa Fe. ${ }^{1}$

\section{Esclavitud y derecho}

6 Durante siglos, la regulación de la esclavitud africana en el mundo hispano no se realizó a través de corpus jurídicos específicos. Distintas normas del derecho romano recuperadas en las Partidas, cédulas especiales y una multiplicidad de reglamentos y usos locales daban forma a un complejo y negociado derecho de y sobre los esclavos. En este ordenamiento se preveían derechos como los de casarse, recibir vestimenta, poder cambiar de amo, comprar la propia libertad (incluso en cuotas), denunciar al amo por malos tratos, recibir cuidados durante una enfermedad y la vejez, etc.

7 Una vasta tradición abonó entonces la idea de que la esclavitud hispana era "benigna", especialmente en comparación con la anglosajona. En Argentina, tempranamente políticos e intelectuales medulares en el proceso de formación nacional reforzaron el relato de una esclavitud laxa, temporal y reversible en una sociedad tempranamente democrática, igualitaria y abierta. ${ }^{2}$ Más tarde, el libro de Frank Tannenbaum Slave and Citizen. The negro in the Americas (1946) puso un nuevo ladrillo en esta construcción. Al comparar los sistemas legales anglosajón e iberoamericano sobre esclavitud, el sociólogo norteamericano sostuvo que la doctrina de la "personalidad moral" de los esclavos que existía en el segundo hacía que los esclavizados fueran considerados miembros de la comunidad cristiana con derecho a recibir sacramentos y protección (por la ley, la costumbre y la iglesia) para sus casamientos y familias. Mientras que ello habría aceitado las vías para su acceso a la libertad y habría permitido una posterior integración ciudadana de los negros a la sociedad iberoamericana, la ausencia de tal tradición en las colonias anglosajonas (Indias Occidentales y Norteamérica) había permitido que los dueños de plantación definieran a los esclavos como cosas, les negaran toda protección jurídica y dificultaran sus posibilidades de manumisión y acceso a la ciudadanía.

Los argumentos de Tannenbaum recibieron en lo sucesivo múltiples críticas. No sólo se discutió la ausencia de tales regulaciones en el mundo anglosajón, sino también las afirmaciones sobre el carácter "benévolo", en términos relativos, de la esclavitud iberoamericana y la suposición de que la existencia de tales tradiciones legales equivalían a que fueran respetadas en las colonias y modularan la experiencia efectiva de los esclavizados (De la Fuente, 2004). Más allá de la futilidad de los intentos de comparar sufrimientos esclavos, este debate sirvió para poner en el centro de la escena la importancia de considerar los sistemas jurídicos a la hora de estudiar la esclavitud, resaltar la utilidad de la comparación y llamar la atención sobre de los diálogos y los 
préstamos que se establecieron entre las distintas experiencias a la hora de abolir esta institución.

9 En los siglos XVIII y XIX, en un mundo atlántico en acelerada transformación, la redacción de leyes sobre esclavos y libertos se multiplicó. La liberación hispana de la trata, por un lado, y el ímpetu regulador ilustrado, por el otro, impulsaron en el nuevo mundo la voluntad de sistematizar reglas sobre el uso y trato de los esclavos. Paralelamente, el avance de la sensibilidad y de los movimientos anti-esclavistas promovieron ensayos legales y diálogos sobre los modos ideales de acabar con esta “institución peculiar" y regular la vida de los emancipados.

10 Ambas tradiciones legales -la ilustrada que buscó sistematizar las normas sobre la esclavitud, y la abolicionista que persiguió reglar su fin- confluyen y contribuyen a comprender el Reglamento para educación y ejercicio de los libertos.

\section{Políticas de abolición gradual en el Río de la Plata: tradición e innovación}

\subsection{La tradición ilustrada de los "códigos negros"}

11 El auge del tráfico hispano y el consecuente crecimiento de la población africana y afrodescendiente en las colonias, como mencionamos, inspiraron la redacción de normas específicas sobre esclavos por parte de las distintas coronas (Lucena Salmoral, 1996). Estas leyes, sin embargo, no se limitaron a marcar derechos y deberes de los esclavizados sino también de la población negra y/o mulata libre.

El ejemplo más acabado de este tipo de normativa fue el llamado Code Noir francés de 1685 (Peabody y Grinberg, 2007). Bajo esta inspiración -y presumiblemente buscando emular los resultados económicos de las colonias galas- en los dominios hispanoamericanos se ensayaron distintas ordenanzas y reglamentos sobre negros en general y esclavizados en particular (Lucena Salmoral, 1996). Estas leyes buscaron gobernar la circulación y el uso de los esclavos, impedir delitos y perseguir el cimarronaje. Lejos de reforzar del poder de los amos, sin embargo, declaraban propender al buen trato, la evangelización y el respeto de los derechos que los esclavos tenían en el disperso ordenamiento jurídico hispano. Fue por ello que estas ordenanzas fueron muchas veces resistidas por los dueños de esclavos y dejadas "sin efectos" por la Corona.

Un buen ejemplo de ello fue la llamada Instrucción para educación, trato y ocupaciones de los esclavos de 1789. Redactada por Don Antonio Porlier por orden de la Junta de Estado, ${ }^{3}$ esta Instrucción, más que innovar intentaba hacer accesible la legislación vigente al multiplicado número de dueños de cautivos que la apertura del tráfico había generado (Levaggi, 1973). Ciertas provisiones (como las que fijaban los horarios y tipo de labores que los cautivos podían realizar, las formas en que debían dormir y celebrar o la cantidad y modos de azote que los amos y capataces estaban autorizados a dar) fueron consideradas demasiado específicas para ser aplicables a lo largo del Imperio. Ellas generaron entonces una ola de protestas que desembocaron en su abandono. Esta instrucción guarda algunas semejanzas con el Reglamento de libertos -como la similitud nominativa y el tipo de cuestiones reguladas- pero una diferencia sustancial: el reglamento rioplatense reglaba la vida de personas declaradas libres al nacer. 


\subsection{La tradición abolicionista y de control de los emancipados}

14 Las críticas religiosas (centralmente cuáqueras) y filosóficas (ilustradas) a la esclavitud como institución inmoral cumplieron un rol clave en su deslegitimación pero fue la era de las revoluciones y sus discursos iusnaturalistas los que conformaron el escenario donde las ideas anti-esclavistas se expandieron y las políticas abolicionistas se ensayaron. (Brion Davis, 1975).

La campaña más activa y exitosa fue dirigida contra el tráfico transatlántico de personas y desembocó, por un lado, en la prohibición de la trata por el gobierno británico y, por el otro, en la progresiva instalación de dispositivos de control para el cumplimiento y la aceptación de la medida por parte de otros países. Los abolicionistas (del tráfico) fundaron organizaciones, hicieron fuertes campañas y hacia mediados del siglo XIX lograron que se pusiera fin a un comercio que a lo largo de cuatro siglos redundó en el traslado forzado de al menos doce millones de personas desde el continente africano a Europa y las Américas (Drescher, 2009).

La circulación de estos discursos no fue profusa en el Río de la Plata y tampoco lo fueron las posiciones pro-esclavistas. Quizás por este escaso interés en los debates teóricos, su abolición fue aprobada sin debates por la Convención Constituyente de la Confederación Argentina en 1853. De todos modos, la abolición de la esclavitud en la Argentina no se redujo a ese simple acto jurídico, fue un proceso. Una serie de leyes y políticas que afectaron la definición de la condición jurídica de las personas y también su consideración social, su trabajo, su familia y su vivienda. Para pensar este proceso hay otras dos leyes a tener en cuenta: la abolición del tráfico trasatlántico de esclavos en 1812 (con sus múltiples idas y vueltas) y la -llamada luego- "ley de vientre libre" de febrero de 1813.

17 Ambas medidas fueron parte de un repertorio de políticas graduales de abolición que se extendieron en diversas latitudes del Atlántico desde fines del siglo anterior. En ese repertorio, la regulación de la libertad de los emancipados -como veremos- tuvo un rol central y modalidades diversas.

Los primeros estados de Norteamérica en abolir gradualmente la esclavitud redactaron leyes especiales previendo un acceso progresivo a la libertad. Como reseñaba un observador contemporáneo, el abolicionista francés Brissot de Warville, los estadounidenses "temen que si los negros se vuelven libres causarán problemas; al liberarlos no saben qué rango asignarles en la sociedad; si establecerlos en distritos separados o enviarlos fuera del país" (Citado en Schneider y Schneider, 2007: 249). Las ansiedades que despertaba en las élites la perspectiva de abolir eran muchas -incluso antes de la revolución haitiana y en lugares con poblaciones esclavizadas relativamente reducidas-. Los parlamentos estaduales debatían si los antiguos esclavos y amos podrían vivir juntos como iguales; si los primeros, sumidos largamente en la obediencia y la dependencia, podrían mantenerse a sí mismos una vez liberados, si trabajarían si nadie les obligaba. Si debían disfrutar de los beneficios de la ciudadanía, incluso el derecho a sufragar y ser electos. Si las preguntas fueron casi idénticas en los diversos países, no lo fueron las respuestas ni los tiempos.

19 En el estado de Pennsylvania, por ejemplo, la combinación de esos temores con las miradas "filantrópicas" se reflejaron en la Act for the gradual abolition of slavery dictada en 1780. Esta ley fue una de las primeras en prohibir la esclavitud de los vientres con un 
sistema que devino un modelo para otros estados. La ley establecía que los hijos de madres esclavas nacerían libres pero quedarían por veintiocho años bajo la tutela de los amos de aquellas (sección 4), preveía que se le entregarían útiles para la labranza, y obligaba a los amos a registrar anualmente a los esclavos y niños libertos a su cargo ante los escribanos del condado o ciudad según correspondiera (sección 5). Este tipo de reglas las encontraremos, con algunos cambios, en el Reglamento de 1813.

Disposiciones de este tipo se hicieron corrientes en las aboliciones graduales anglosajonas, incluso en la abolición total de la esclavitud en las colonias británicas en 1833 donde se estableció un sistema de aprendizaje (apprenticeship) para los emancipados -esto es, la obligación de trabajar entre 4 y 7 años para sus antiguos amos (que serían por cierto compensados por la pérdida de su propiedad).

En el mundo hispano el reglamento redactado en Buenos Aires en 1813 fue pionero. La ley chilena de vientres libres dictada en 1811 no había dispuesto ninguna tutela especial sobre los emancipados. No sabemos exactamente qué antecedentes manejaban los redactores rioplatenses (ni quienes fueron específicamente) pero sabemos que las disposiciones por ellos establecidas estuvieron luego presentes en prácticamente todas las leyes declarando libres a los hijos de esclavas (Antioquia de 1814, Colombia, Venezuela, Ecuador y Perú en 1821, Uruguay en 1825) e incluso en algunas leyes de abolición total de la esclavitud (como la de Chile de 1823 o Paraguay de 1870). La gravitación e impacto del Reglamento fue entonces importante no sólo en relación a los libertos rioplatenses sino para sus pares de otras latitudes. ${ }^{4}$

\section{El reglamento rioplatense}

\subsection{Sus disposiciones}

Si bien la ley de febrero declaró "libres" a los niños nacidos de madres esclavizadas, el decreto de marzo estableció que ellos eran "libertos". Lejos de tratarse de una banal diferencia nominal, el nuevo vocablo abría un repertorio amplio de regulaciones sobre la vida de los pequeños "esclavos emancipados" -tal era el significado de la voz "liberto". Al ser considerados tales, la libertad que gozarían era de un tipo muy especial, era una libertad "concedida". Se consideraba que en el vientre materno, esos seres humanos habían sido esclavos y, por lo tanto, tenían una especie de deuda para con sus patrones los amos de sus madres que habían "permitido" su libertad.

Las disposiciones del reglamento se entroncaban así también en la tradición del derecho común y en las Partidas. Tanto las Instituciones de Justiniano como las partidas de Alfonso el Sabio establecían con claridad las diferencias entre personas libres "ingenuas" y "libertas". ${ }^{5}$ Estas últimas eran personas redimidas de una llamada "justa servidumbre", manumitidas, yello traía aparejada una serie de deberes para con sus antiguos amos.

Así lo explicaba, por ejemplo, el jurista y eclesiástico guatemalteco José María Álvarez en su best-seller Instituciones de derecho real de Castilla y de Indias. El fundamento del patronato, sostenía Álvarez, reside "en cierta especie de paternidad y filiación que el derecho finje entre el patrono y su liberto. La razón es clara: porque asi como el hijo debe á su padre la vida natural, el liberto debe á su patrono la civil". ${ }^{6}$ Álvarez, como la mayor parte de la doctrina hispanoamericana, señalaba que esos deberes se hallaban desusados, 
"desacostumbrados", sin embargo el Reglamento analizado produjo una drástica reactivación en estos.

Los niños emancipados por el decreto de febrero de 1813 fueron puestos bajo el patronato de los amos de sus madres y debieron servirlos gratuitamente por quince años para compensar los gastos de su crianza y mantenimiento. Dicho estatus los acercaba en muchos sentidos a la esclavitud dado que no podían optar dónde y cómo vivir, los amos podían beneficiarse del trabajo gratuito de los menores y disponer de ellos en sus testamentos, podían incluso vender estos derechos a un tercero, aunque significara separarlos de sus madres.

La justificación de esta medida era que, de no existir, los amos de las parturientas no tendrían incentivos para proteger el parto y hacerse responsables por el cuidado de los niños. Efectivamente esas resistencias a los embarazos se produjeron ${ }^{7}$ y la alta mortalidad de bebés libertos da la pauta también de cuanto resistieron los amos cuidar de niños que ya no eran sus esclavos. ${ }^{8}$ También en la prensa se reflejó este problema. ${ }^{9}$

Pasados los primeros años, ya cuando los niños libertos comenzaron a perfilarse como mano de obra semi-cautiva disponible en un contexto de escasez de brazos, fueron muy buscados, su guarda disputada y sus servicios siempre usufructuados.

La aplicación del Reglamento fue estricta en cuanto al aseguro de los derechos de los patrones, no así en cuanto a las previsiones "caritativas" y paternalistas sobre el futuro (útil y controlado) de los libertos. No tenemos certezas sobre si fueron pagados los salarios que debían recibir desde los 15 años los varones y desde los 14 las mujeres. La Tesorería Filantrópica que debía recaudarlos no fue creada, ni se repartieron tierras ni útiles de labranza.

\subsection{Su funcionamiento}

¿Cómo fue aplicado el reglamento? ¿Qué rol tuvo en la modulación de la vida de aquellos hijos de esclavas nacidos luego de 1813 en el Río de la Plata? El derrotero del reglamento fue analizado en la historiografía local en diversos trabajos. En primer lugar, en su clásico libro sobre los afroargentinos, George Reid Andrews enfatizó la ambigüedad de esta figura del liberto y su cercanía a la de esclavo ya que si bien "era el derecho de patronato y el derecho a los servicios del liberto lo que cambiaba de manos... en la práctica era un ser humano al que se estaba vendiendo, a pesar del hecho de que éste pudiera ser teóricamente libre". ${ }^{10}$ En este sentido, Andrews enfatiza el elevado porcentaje de niños negros y mulatos viviendo sin sus progenitores (a diferencia de los blancos) lo que sugiere que efectivamente esa circulación de niños libertos ocurría sin mayores trabas.

En el marco del bicentenario de la revolución se hicieron tres nuevos estudios del reglamento. Liliana Crespi analizó el estatus que llamó "ni esclavo, ni libre" de los diversos tipos de libertos: los manumitidos graciosamente o por auto-compra, los coartados, los rescatados para pelear en las guerras, los libertos por operaciones de corso y los nacidos tras el decreto de libertad de vientres. En el caso de estos tres últimos tipos de libertos, señaló la autora, "el estado republicano se reconoció el derecho a disponer de los libertos como forma de "devolver" al gobierno algo del beneficio que les fuera otorgado" (p. 29). Asimismo, las particularidades del estatus acordado a estas personas, sostiene Crespi, demuestra que los gobiernos republicanos buscaron mantener a los afroargentinos "en un estado de disminución civil" (p. 34). ${ }^{11}$ 
Casi simultáneamente, y en el marco de su tesis de licenciatura, Alejandro Castro abordó la cuestión del cumplimiento o no del Reglamento de libertos. En dicho trabajo señaló diversas estrategias de evasión de los deberes de los amos (anotar libertos como esclavos, resistir que las madres se casen, evitar el pago de los carros de los libertos fallecidos, etc.), diversos conflictos entre éstos y el gobierno (por los entierros, por la crianza de los niños), juicios entre patrones potenciales diversos (por el derecho a los servicios de los niños) y casos de sustracción de libertos de casa de los patrones por familiares o conocidos. ${ }^{12}$

Por mi parte, en un trabajo publicado también en 2010, reseñé los pormenores del reglamento y el carácter vigilado de la libertad pensada para los libertos. Analizando un corpus de demandas judiciales que enfrentaron a esclavos, amos y/o patrones por el futuro de los libertos (centralmente por su guarda y trato) mostré el protagonismo de los libertos y sus familias en la lucha por dar efectividad a los derechos sancionados y resistir los costados más opresivos del Reglamento.

Un conjunto de nuevos casos judiciales analizados nos permite comprender mejor el impacto del Reglamento en la vida de los hijos e hijas de las esclavizadas. Dos cuestiones fundamentales afloran en ellos. En primer lugar, que si bien el Reglamento fue el marco general que pautó su estatus, como señalaron los trabajos reseñados, la definición de los titulares del patronato, la función de éste y la circulación de los libertos se definió muchas veces en la arena judicial en una dinámica más casuista que legalista (esto es, caso por caso a criterio del juez y no mediante una aplicación mecánica del reglamento). En segundo lugar, que los distintos gobiernos y los jueces enfatizaron elementos diversos de la institución del patronato a lo largo de las décadas ajustando su funcionalidad. En el apartado siguiente intentaremos mostrar este funcionamiento y los conflictos centrales en torno a los libertos.

\subsection{Su modulación (judicial) cotidiana}

Los alcances del patronato y sus fines no estuvieron claros inmediatamente para los actores involucrados. Esclavos, libertos, patrones, jueces y policías tenían ideas muchas veces vagas e incluso contrarias sobre las implicancias de esta institución. En la multiplicidad de casos judiciales en torno al patronato encontramos una disputa abierta y respuestas diversas a las preguntas en torno a ¿cuál era el sentido del patronato? ¿Por qué había sido establecido? ¿Era su objetivo asegurar el cuidado de los bebés y niños de las esclavas embarazadas o generar una especie de compensación a los amos por la emancipación de los niños a través de su servicio gratuito? ¿Era asegurar la educación de menores que no "podían" ser preparados para ser ciudadanos por madres esclavas? Todas estas alternativas estuvieron presentes desde el primer día del funcionamiento de la institución pero las respuestas y los énfasis cambiaron con el paso de los años y el crecimiento de los niños.

Fuera el objetivo o no, el "mantenimiento y crianza" de los niños no estuvo garantizado fácilmente. Las causas judiciales nos muestran padres y patrones contendiendo sin cesar sobre el cuidado de los libertos, especialmente cuando ellos no vivían con sus progenitores, ya fuera por haber sido éstos emancipados o vendidos a otra casa. Estas disputas tenían muchas veces origen en el incumplimiento de los deberes legales de los patrones, quienes solían delegar (temporal o permanentemente) el cuidado de los libertos en sus padres, especialmente si éstos eran libres. Como en los casos de emancipación de 
padres ancianos, la liberación de los niños podía funcionar como vía para la desresponsabilización de los amos.

Uno de estos conflictos enfrentó en 1822 al esclavo Manuel Pacheco y la patrona de su hija, doña Cayetana Alvarez. En marzo de 1822 Pacheco expuso ante la justicia ordinaria que hacía más de tres años, quien fuera ama de su difunta esposa y patrona de su hija liberta Juana Paula, le había entregado la niña. Explicaba que como "las enfermedades del marido de D Cayetana no le permitiesen lugar para cuydar de la criatura, se lleno esta de llagas y de lepra y se puso tan estenuada que por evitarse de pagar su entierro tuvo a bien llamarme y entregarmela para que la mandara a curar y la mantuviera". ${ }^{13}$ Pacheco relataba que "como padre" había hecho "quantas diligencias eran imaginables", pagando "facultativos y curanderas". Pero quando doña Álvarez la vio "crecer sana y util para servicio"... "me la ha pedido judicialmente" ${ }^{14}$ A pesar de su negativa, el Juez de paz lo compelió a entregar la niña y el camarista Juez de Alzada lo confirmó. Al ser éste un asunto juzgado, lo que Pacheco reclamaba era que se le abonaran los gastos hechos en las curaciones, 150 pesos.

El juez de primera instancia Bartolomé Cueto decidió entonces llamar a juicio oral y allí se acordó pedir información sobre el proceso anterior. La causa tomó en adelante un rumbo diferente y salieron a la luz hechos desconocidos. Pacheco presentó el certificado del juez que en 1819 atestiguó el estado crítico de la niña. A su vez, adjuntó otro del defensor de menores que en 1821 había arreglado que la niña fuera depositada en "alguna casa de reconocida honradez" mientras se resolvía la disputa sobre su tenencia, dado que había resultado "comprobada la sevicia q D Cayetana usaba con la negrita hasta el extremo de ponerla en el estado de muerte por su desmedida crueldad". ${ }^{15} \mathrm{~A}$ esta altura el esclavo dejó de reclamar el dinero para solicitar que se lo amparase en la posesión de su hija y se dictase perpetuo silencio a Álvarez. Como en tantos otros casos desconocemos la resolución final pero la causa se interrumpe con la provisión de Cueto de que la niña permanezca con el padre hasta la resolución definitiva. La sevicia era causa prevista para el cese del patronato de acuerdo al artículo séptimo del "Reglamento" por lo que es probable que Pacheco conservara la patria potestad de su hija.

No había forma de comprobar que los patrones cumplieran con sus obligaciones de tales. Cayetana Álvarez no había mantenido a la liberta por tres años y la había recuperado al reclamarla. Sólo las eventuales quejas y solicitudes de los padres podían alertar sobre esta situación. Manuel Pacheco no había siquiera denunciado por sevicia a la patrona de su hija, y es probable que el deseo de permanecer con la niña o el temor hacia la señora lo hubieran disuadido. En relaciones que podían ser tan desiguales era difícil asegurar los derechos y hasta siquiera el bienestar de los menores.

No eran pocos los patrones que cedían sus deberes. En 1835, el defensor general de menores, a nombre de Teresa Dorna, presentó un recurso a la justicia. Emancipada por su ama al morir, Teresa había estado a cargo de su hijo liberto Juan Francisco desde sus ocho años. El joven acababa de cumplir 16 y según su madre, justo "quando es importante colocarlo con ventaja en algun oficio útil" ${ }^{16}$ el patrón legal del niño, don Zenon Videla, había aparecido para reclamarlo. El defensor pedía que se oyera a Videla y, "de ser esto cierto", se envíe el niño a su cargo (del defensor) para cuidar "de su mejor colocación". En su respuesta Videla negó, en primer lugar, "haber cedido el derecho que la ley me acuerda" sobre el liberto. ${ }^{17}$ Sostuvo que lo dejó bajo el cuidado de su madre en ocasión de un viaje a la Banda Oriental y que por consideración a "que dicha negra habia sido de mi casa"18 no lo había reclamado al regresar. Sin embargo, agregaba, años más tarde Teresa, "conociendo mis derechos, como patrono de su hijo y no pudiendo contener al negrillo 
que le daba mucho trabajo"19 y que se le había huido varias veces, se lo devolvió motu proprio. Al recibirlo, argüía Videla, percibió que el joven había adquirido "los detestables vicios de la embriaguez, y no le duraba ropa alguna porque toda la jugaba" ${ }^{20}$ Por esta razón decidió apartarlo del "trato y comunicación de aquello que podria acabar por perderlo" y se lo entregó a su sobrino José María González para que lo ocupase en los trabajos rurales de su establecimiento al otro lado del Puente de la restauración. Allí estaba conchabado por 15 pesos mensuales -aseguraba Videla- $y$ auxiliaba a su madre. A su vez, aseguraba que "Se ha pensado y lo llevamos a afecto, que descontandole mensualmente, una parte de sus jornales, se le cree un fondo para cuando llegue a la edad de la emancipación". Esta estrategia de guardar una parte de sus jornales para el momento de su emancipación completa era la realización de una "tesorería filantrópica" privada. Videla cnocía la ley, había sido miembro de la Junta de Representantes de la provincia de Buenos Aires y sabía cómo debía mostrarse un patrón responsable. ${ }^{21}$ Para asegurar sus "derechos", a su vez, echaba un manto de sospecha sobre Teresa. Alegaba que eran sabidos "los males que le sobrevendrán [al joven] yendo a poder de una madre, incapaz de contenerlo en sus extravíos y también de educarlo en los principios de una buena moral". ${ }^{22}$ Finalmente, aseguraba que incluso el padre del liberto prefería que este permaneciera a su cargo. El conflicto fue resuelto en un comparendo verbal propuesto por el defensor, cuyo resultado no está asentado pero no es arriesgado suponer favorable al gran hacendado. El defensor y el patrón coincidían en alegatos en los que la preocupación central era asegurar la laboriosidad y la disciplina de Juan Francisco.

El patronato, no era entonces sólo un mecanismo de compensación para los amos y de garantía de cuidado de los libertos, era también una estrategia de control de las poblaciones de origen africano libre. Quien quisiera conservar el patronato debía mostrar que estaba en condiciones de asegurar ese objetivo.

Si muchas veces los conflictos enfrentaban a los padres con los patrones, otras veces dos posibles patrones se disputaban el cuidado, y sobre todo los servicios, de los libertos. En marzo de 1824 Joaquina Gomes recurrió al juzgado de primera instancia solicitando que le fuera entregada la hija liberta de una esclava que comprara meses atrás. La niña, llamada Juana, se encontraba con el anterior amo de su madre, Juan Vitón, aunque de acuerdo a Gomes, al venderla éstos habían cedido el patronato a la esclava. En la disputa en cuestión, no conocemos la voz (o siquiera el nombre) de esa madre esclava, sólo "escuchamos" a los amos.

Por un lado, Joaquina Gomes. En su versión, su interés no era más que reunir a su afligida esclava con su hija. Sabemos de esta aflicción por un primer intento de la esclava por recuperar a su hija. De todos modos es posible suponer que Gomes también deseaba ganar, con una misma compra, una esclava y un sirviente extra. ${ }^{23}$

Por el otro lado, se encontraba el antiguo amo. En poder de la niña desde hacía años, Vitón adujo a lo largo del proceso varios tipos de razones para evitar que se retire "de su honrada y conocida casa a la liverta en cuestión". ${ }^{24}$ En su primer respuesta judicial declaró que no era "regular" tener que perder el empeño puesto en la educación de Juana, "hasta pagarle la escuela pa qe le enseñasen con perfeccion, a leer y coser". ${ }^{25}$ Más avanzadas las indagaciones llegó a decir que no quería dejarla ir "por el amor que le tenia" lo que lo había llevado a tener con ella "cualquier finesa hecha a un hijo". Finalmente sostuvo que no quería que se dijese que no había cumplido sus deberes para "con esa clase de criaturas". Un repertorio de argumentos de diverso cuño confluía para asegurar la conservación del patronato. 
Frente a estas posturas encontradas, el juez pidió nuevas opiniones. Ninguna a la madre esclava, ninguna a Juana. Fueron consultados el juez de paz de la parroquia, Julián Panelo, y el defensor de menores. El primero había sido la autoridad a quien la esclava había recurrido tiempo atrás para reclamar a su hija. Panelo justificó su decisión de dejar a Juana con Vitón alegando que sólo fue fiel a la voluntad del gobierno que "ha encargado a los Juzgados el cuidado de los libertos con repetidas órdenes con el objeto unico de $q$ adelanten en las Casas q les puso por destino, pa que en adelante sean utiles al Pais". ${ }^{26}$ Para el juez de paz el objeto del patronato era asegurar que los menores fueran personas útiles, futuros buenos trabajadores. Las órdenes del gobierno y la "prudencia" de los jueces debían velar por ello. El juez afirmaba entonces que había tomado "todas las medidas que me dicta la prudencia para llenar el deseo del Govno; y he aqui una delas que he creido será capaz de aquellos objetos". ${ }^{27}$ Quizás por ello, el juez no indagó si realmente Vitón había entregado la potestad sobre Juana con la escritura de venta de su madre (como muchas veces sucedía y como Gomes afirmaba que había sucedido). Si era así, el viejo amo no habría tenido ningún derecho sobre la niña y toda la disputa carecía de sentido.

El segundo funcionario consultado en la causa, el defensor de menores, preguntó por el tiempo que hacía que la esclava había mudado de amos. Al saber que no era mucho, propuso que la niña permaneciera con Vitón por un año y si su madre permanecía por un año con la nueva ama, Juana podría luego ir con ellas. Más que la aplicación de la ley fue una serie de interpretaciones sobre los objetivos del gobierno, la finalidad de la ley y los derechos adquiridos por los diversos patrones, impulsó la adopción de una decisión adhoc y en perjuicio de la reunión de la familia.

En este caso, como en muchos otros, la capacidad de negociación de la esclava fue realmente limitada así como limitado fue el apego a la regulación del patronato. La imposibilidad de disponer sobre el propio destino se trasladó de los esclavos a sus hijos libertos y sus vidas fueron definidas en un complejo torbellino de interpretaciones sobre el contenido de la ley, las intenciones del gobierno y los deberes de los jueces.

Estos casos ejemplifican algunos de los conflictos y negociaciones abiertos por el reimpulso que la regulación del derecho al patronato generó en el Río de la Plata. Ellos muestran cómo los perfiles concretos de la relación fueron disputados y definidos sobre una base cotidiana, con amplios márgenes de negociación por parte de los actores y de decisión discrecional por parte de gobernantes y jueces. El Reglamento que fue la norma de fondo que legitimó la apropiación gratuita del trabajo de miles de niños que habían sido declarados "libres" en febrero de 1813 y dilató el acceso a la libertad plena de las poblaciones de color libre. De todos modos su funcionamiento no fue mecánico sino que abrió todo un campo de disputas en torno a los derechos de niños y padres.

El Reglamento estableció un mecanismo de compensación a los amos por la "pérdida" de sus propiedades humanas decretada por el gobierno y, en cierto sentido, estos niños y jóvenes pagaron su libertad con su cuerpo y con su tiempo. La modalidad queda explicada en el documento que aquí reproducimos.

\section{El texto del reglamento}

Art $1^{\circ}$ Para que no pueda cometerse el menor fraude en este particular, deberá ordenarse á todos los párrocos que pasen mensualmente al Intendente de Policía ó Juez respectivo de este ramo, y en los lugares ó pueblos de la campaña á las justicias ordinarias, una razón 
de los niños de castas que hayan bautizado, con espresion de sexo, cuartel y nombre de sus padres y patrones.

-Art. $2^{\circ}$ Los cabezas de familia, en cuya casa naciere algún niño de esta clase, deberán en las ciudades pasar una noticia circunstanciada dentro de tercero dia, a lo más, de su nacimiento, al alcalde respectivo de su cuartel, quien deberá dar cuenta cada mes al Intendente de Policía ó Juez, con la razón que hubiesen pasado los vecinos; bien entendido que en ella deberá expresarse el número del cuartel y manzana, ó anotarse distintamente la casa ó barrio, donde no hubiere esta división y también el nombre de sus padres, con la precisa circunstancia de si son libres, ó esclavos de que pertenencia. Los habitantes de los pueblos de campaña tendrán el mismo término perentorio para pasar dicha razón a las justicias respectivas y los que habiten fuera del poblado la pasarán a éstas dentro del término perentorio, que deberán establecer los gobiernos respectivos, á virtud de informes convenientes; dichos Gobiernos fijarán a sí mismo el término, en que las justicias de la campaña deben pasar a la Policía respectiva, dicha razón.

34 -Art. $3^{\circ}$ Del mismo modo deberán pasar los párrocos á dicha Policía mensualmente la razón de los que de esta clase hubiesen sepultado; de las ciudades estarán obligados a pasar á lo menos dentro de tercero día la misma razón á los alcaldes de los cuarteles, para que estos la pasen a la Policía mensualmente. Los habitantes de los pueblos de la campaña pasarán esta razón a las justicias dentro de tercero día y los que habiten fuera de poblado en el término que establecieren los Gobiernos respectivos. Las justicias de la campaña pasarán también esta razón a la Policía respectiva dentro del término que acordaren los Gobiernos de las Provincias respectivas según el artículo antecedente.

-Art. $4^{\circ}$ La lactación de los infantes libertos deberá durar doce meses por lo menos.

-Art. $5^{\circ}$ Cuando se hubiese de vender una esclava, que tenga un hijo liberto, deberá pasar con él a poder del nuevo amo si el liberto no hubiese cumplido aún los dos años; pero pasado este tiempo, será á voluntad del vendedor el quedarse con él, ó traspasarlo al comprador con la esclava.

37 -Art $6^{\circ}$ Todos los niños de castas, que nacen libres, deberán permanecer en casa de sus patrones hasta la edad de veinte años.

38 -Art. $7^{\circ}$ No tendrá lugar el artículo antecedente; si los libertos fuesen tratados con sevicia por sus patrones, pues justificado que sea ante la Policía, deberá ésta destinarlos á la casa que reulase más conveniente.

39 -Art. $8^{\circ}$ Los libertos servirán gratis á sus patrones hasta la edad de 15 años y en los cinco restantes se le abonará un peso cada mes por su servicio, siendo de cuenta de sus patrones la demás asistencia.

40 -Art. $9^{\circ}$ Cada mes deberán entregar el contingente del salario todos los vecinos por el número de libertos que tuviesen.

41 -Art. $10^{\circ}$ Se creará una tesorería con el nombre de Tesorería Filantrópica, y en esta serán percibidos los salarios de todos los libertos.

42 -Art. $11^{\circ} \mathrm{El}$ destino, ó profesión que hayan de tener los libertos cumplidos los 20 años, será del arbitrio de ellos mismos, cuidando el Intendente de Policía que no vaguen con perjuicio del Estado.

43 -Art $12^{\circ}$ Cumpliendo el liberto los 20 años de su edad, deberá desde el mismo día ser emancipado de su patrono y darse cuenta a la Policía. 
44 -Art. $13^{\circ} \mathrm{A}$ cada liberto varón que prefiriese la labranza se le darán por el Estado cuadro cuadras cuadradas de terreno en propiedad.

-Art $14^{\circ}$ No podrá señalarse al liberto el establecimiento en la campaña, ni ponerse en su posesión sin que se case con libre o liberta, si antes no lo hubiese verificado.

-Art. $15^{\circ}$ Las libertad quedarán emancipadas a los 16 años o antes si se casasen y desde los 14 deberá abonárseles por sus servicios un peso mensual, que del mismo entregarán sus patrones en la Tesorería Filantrópica.

47 -Art $16^{\circ}$ Con el fondo resultante del servicio de ambos sexos se comprarán al liberto que quisiese destinarse a la labranza, los útiles y aperos necesarios para su establecimiento; se le darán los materiales para construir su casa, las semillas precisas para sus primeros cultivos y la primera cosecha.

-Art. $17^{\circ}$ De las cuatro cuadras cuadradas que se donan a cada liberto que se dedicare a la labranza, deberán tener en el término preciso de dos años, una cuadra cuadrada por lo menos de monte y otra labrada y sembrada.

-Art. $18^{\circ}$ Siendo este un establecimiento filantrópico y a efecto de no cargar los fondos que resulten del jornal de los libertos, deberá crearse una Junta de Piedad de los vecinos más honrados y rolar entre ellos por determinado tiempo los cargos de su manejo, bajo la inspección inmediata de la policía.

50 -Art $19^{\circ}$ El señalamiento del terreno que deberá darse á los libertos será de la inspección de la Policía. El Intendente General de ella en esta ciudad podrá cometerlo a sus comisarios, y en las demás los jueces encargados de este ramo á las justicias territoriales, quienes deberán darles cuenta de la conducta de los libertos en el manejo de su labranza, para que se anote en un libro y pueda conocerse desde luego el grado de laboriosidad de cada uno y tomar en su vista las providencias que se estimen necesarias para el mayor adelantamiento del trabajo.

51 -Art $20^{\circ}$ Desde el 27 de Febrero de 1813, inclusive en adelante, deberán ser bautizados gratis todos los niños de castas que nacieren dentro del territorio de las Provincias Unidas del Río de la Plata.

52 -Art $21^{\circ}$ Del mismo modo serán enterrados gratis por los Párrocos de todas las Iglesias de las Provincias Unidas todos los libertos que muriesen hasta el punto de su emancipación, debiendo tener toda su fuerza obligatoria el presente artículo desde el 3 de marzo de 1813, inclusive.

53 -Art $22^{\circ}$ Estas soberanas disposiciones serán observadas y cumplidas puntualmente en todo el territorio de las Provincias Unidas del Río de la Plata, á cuyo reglamento, firmado por nuestro Diputado Presidente en turno y refrendado por nuestro secretario más antiguo.

Buenos Aires á 6 de Marzo de 1813

Tomás Antonio Valle, Presidente. Hipólito Vieytes, Diputado Secretario - Es copia.

\section{Comentarios finales}

El reglamento nos permite observar cómo las instituciones jurídicas crearon y mediaron la categoría de libertad en el dinámico período de las revoluciones atlánticas, la independencia y la abolición. 
En el reglamento rioplatense se conjugaron diversas tradiciones jurídicas: por un lado, la tradición ilustrada de escribir "códigos negros", esto es, conjuntos de leyes destinadas a regular el uso del tiempo y trato de las poblaciones de color, esclavizadas o no, y, por otro lado, la tradición más propiamente abolicionista que a lo largo y ancho del atlántico conjugó las políticas de abolición gradual con la previsión de un acceso lento y controlado a la libertad por parte de los africanos y afrodescendientes.

En la América hispana el Reglamento fue pionero e introdujo un conjunto de disposiciones "benéficas" y al mismo tiempo de control de las poblaciones de color que serían retomadas más tarde en otras experiencias.

Documentos como el trascrito permiten enfatizar el carácter gradual y complejo del proceso de abolición y acercarnos a las luchas que debieron afrontar los emancipados para lograr la libertad -una libertad legalizada que no coincidió con la esperada e imaginada. En el largo plazo, conocer estas disposiciones puede contribuir a reflexionar sobre el impacto que este tipo de disposiciones tuvo sobre la construcción de las identidades de los afrodescendientes. Sometidos a controles especiales como los dispuestos en el reglamento de libertos, las restricciones especiales para el sufragio activo y pasivo de afrodescendientes, y los posteriores reglamentos de sociedades africanas, no parece difícil imaginar que la reivindicación de una identidad anclada en África o en la condición de negro no era fácil de sostener en la Buenos Aires posrevolucionaria.

La celebración local del mestizaje se construyó sobre la base (y olvido) de este tipo políticas que etnizaron y subalternizaron el pasado esclavo y la afrodescendencia. Los relatos oficiales sobre el carácter benigno de la esclavitud y sobre la integración igualitaria de los afrodescendientes hunden sus raíces en un imaginario paternalista que las disposiciones del Reglamento no pueden mostrar más claramente.

\section{Fuentes}

Registro Oficial de Leyes de la República Argentina (R.O.R.A.) Tomo I, 1810-1821, Buenos Aires, Imprenta La República, 1879, pp. 200-201

La Gaceta de Buenos Aires, № 48, 10 de marzo de 1813.

La Prensa Argentina, $\mathrm{N}^{\circ}$ 23, 20 de febrero de 1816

Archivo General de la Nación (AGN), Sala IX, 23-8-4

AGN, Sala IX, Administrativos, Legajo 30, Expediente 1020

AGN, Sala IX, 39-8-4, 1815

AGN, Sala IX, 23-8-3, 1813

\section{BIBLIOGRAPHY}

Brion Davis, D. (1975). The problem of Slavery in the Age of Revolution, 1770-1823, Ithaca, London: Cornell University Press. 
Candioti, M. (2015). Regulando el fin de la esclavitud. Diálogos, innovaciones y disputas jurídicas en las nuevas repúblicas sudamericanas 1810-1830, Jahrbuch für Geschichte Lateinamerikas, (52): 149-172.

De la Fuente, A. (2004). Slave Law and Claims-Making in Cuba: The Tannenbaum Debate Revisited, Law and History Review, (22):339-369.

Drescher, S. (2009). Abolition: a History of Slavery and Antislavery, Cambridge-New York: Cambridge University Press.

Goldberg, M. (1976). La población negra y mulata de la ciudad de Buenos Aires, 1810-1840", Desarrollo Económico, XVI (61):77-99.

Levaggi, A. (1973). La condición jurídica del esclavo en la época hispánica, Revista de Historia del Derecho (1): 83-175.

Lucena Salmoral, M. (1996). Los códigos negros de la América hispana, Alcalá de Henares: Ediciones UNESCO/Universidad de Alcalá.

Peabody, S. y Grinberg, K. (2007). Slavery, Freedom, and the Law in the Atlantic World. A Brief History with Documents, New York: Bedford Book.

Rebagliatti, L. (2014). ¿Una esclavitud benigna? La historiografía sobre la naturaleza de la esclavitud rioplatense, Andes. Antropología e historia, (24): 1-29.

Schneider, C. y Schneider, D. (2007). Slavery in America, New York, Infobase Publishing.

Tannenbaum, F. (1963 [1946]). Slave and Citizen. The Negro in the Americas, New York: Random House.

\section{NOTES}

1. Los comienzos de esta investigación fueron posibles gracias a la beca de la Fundación Slicher Van Bath de Jong para la promoción del estudio y la investigación de la historia de América Latina (2014) y actualmente se desarrolla en el marco del PICT 2014-2097 "Esclavitud y abolición en Buenos Aires y Santa Fe: perspectivas comparadas sobre el proceso de erosión de la institución esclavista en las primeras décadas republicanas (1810-1853)".

2. Sobre las posturas coincidentes en este sentido de Mitre y López a la historiografía de los años '60 y '70, pasando por la historia del derecho y el revisionismo cfr. Rebagliatti, 2014.

3. Sobre Porlier cfr. Lucena Salmoral, 1996, pp. 98-100.

4. Para una comparación sobre las estrategias de abolición y control de emancipados en Chile, Argentina y Colombia cfr. Candioti (2015).

5. Instituciones de Justiniano, Buenos Aires, Editorial Heliasta, 2005, p. 27-29.

6. Instituciones de Justiniano, Buenos Aires, Editorial Heliasta, 2005, p. 37

7. Ver al respecto, entre otros Archivo General de la Nación (AGN), Sala IX, 23-8-4, Administrativos, Legajo 30 Expediente 1020, IX, 39-8-4, 1815 y 23-8-3, 1813.

8. La Gaceta de Buenos Aires, $n 55,11 / 03 / 1816$. Un análisis sobre la mortalidad de los libertos en Goldberg (1976: 88).

9. En un artículo remitido a La Prensa Argentina en 1816 se denunciaba la práctica de los dueños de esclavos de "no permitir a estos que se casen, a pretexto de las incomodidades que pueden resultarles de la crianza de los libertos”. La Prensa Argentina, $\mathrm{N}^{\circ} 23,20 / 02 / 1816$.

10. Andrews, George Reid, Los afroargentinos de Buenos Aires, Buenos Aires, Ediciones de la Flor, 1989 p. 59. 
11. Crespi, Liliana "Ni esclavo, ni libre. El status del liberto en el Río de la Plata desde el período indiano al republicano", en Mallo, Silvia y Telesca, Ignacio (ed.), "Negros de la Patria": Los afrodescendientes en las luchas por la independencia en el antiguo Virreinato del Río de la Plata, Buenos Aires, Editorial SB, Colección Paradigma Indicial, pp. 39-61. La autora también realizó interesantes trabajos sobre las operaciones de corso en general y sobre comercio y contrabando de esclavos en la colonia.

12. Algunos trabajos abordaron la aplicación del decreto de libertad de vientres en la Banda OrientalAna Frega analizó la vigencia de la ley en territorios artiguistas y mostró que también allí fue necesario recurrir a los tribunales para hacer efectiva la libertad declarada y, en particular, "que los amos intentaron aprovechar en su favor la superposición o sucesión de autoridades en la Banda Oriental" Frega, A, "Caminos de libertad en tiempos de revolución. Los esclavos en la Provincia Oriental Artiguista, 1815-1820", en Arturo Bentancur, Alex Borucki y Ana Frega, compiladores, Estudios sobre la cultura afro-rioplatense. Historia y presente. Montevideo, Dpto. de Publicaciones, FHCE, 2004, pp. 49.

13. AGN, TC, P-11, 1822, El moreno Manuel Pacheco contra D Cayetana Alvarez sobre una hija, f. 1.

14. AGN, TC, P-11, 1822, El moreno Manuel Pacheco contra D Cayetana Alvarez sobre una hija, f. 1.

15. AGN, TC, P-11, 1822, El moreno Manuel Pacheco contra D Cayetana Alvarez sobre una hija, f. 4.

16. AGN, TC, D - 11, 1835-1836, Defensor Gral de Menores, contra Videla Zenon por el patronato de Dorna Juan Francisco, f. 1.

17. AGN, TC, D - 11, 1835-1836, Defensor Gral de Menores, contra Videla Zenon por el patronato de Dorna Juan Francisco, f. 2.

18. AGN, TC, D - 11, 1835-1836, Defensor Gral de Menores, contra Videla Zenon por el patronato de Dorna Juan Francisco, f. 2.

19. AGN, TC, D - 11, 1835-1836, Defensor Gral de Menores, contra Videla Zenon por el patronato de Dorna Juan Francisco, f. 2.

20. AGN, TC, D - 11, 1835-1836, Defensor Gral de Menores, contra Videla Zenon por el patronato de Dorna Juan Francisco, f. 2.

21. El clan Videla-Dorna era uno de los más poderosos de la provincia, especialmente luego del casamiento de Zenón con Sandalia Dorna el que aseguró la unión de dos enormes terratenientes. Sobre la militancia unitaria de Videla cfr. gnacio Zubizarreta, "Unitarios en la campaña bonaerense: vínculos y construcción política en un territorio adverso, 1820-1829 ", Nuevo Mundo Mundos Nuevos [En línea], Debates, Puesto en línea el 14 diciembre 2012, consultado el 19 enero 2013. URL : http://nuevomundo.revues.org/64583 ; DOI : 10.4000/nuevomundo.64583

22. AGN, TC, D - 11, 1835-1836, f. 3v.

23. Los anuncios en los periódicos daban cuenta de estos servicios extra. Como ejemplo podemos mencionar el publicado

24. AGN, TC, G-14, 1824-25, Joaquina Gomes apelando de una providencia del juez de paz de la catedral, f. 4.

25. AGN, TC, G-14, 1824-25, Joaquina Gomes apelando de una providencia del juez de paz de la catedral, f. 4.

26. AGN, TC, G-14, 1824-25, Joaquina Gomes apelando de una providencia del juez de paz de la catedral, f. 3.

27. AGN, TC, G-14, 1824-25, Joaquina Gomes apelando de una providencia del juez de paz de la catedral, f. 3. 


\section{ABSTRACTS}

The Education and exercise of the freedmen Act of 1813 was drafted by the Constituent Assembly immediately after having sanctioned the Decree "declaring free the children of slaves". This is a fundamental piece to understand the gradual nature of the abolition of slavery and citizen inclusion of African descendants in the Rio de la Plata. The twenty-two articles show that the attainment of freedom for the children of enslaved women was not immediate or full as they were put on a special minority regime that left them subject to the masters of their mothers and police special inspections.

El Reglamento para la educación y ejercicio de los libertos de 1813 fue redactado el 6 de marzo por la Asamblea Constituyente luego de haber sancionado el 3 de febrero un "Decreto declarando libres a los hijos de las esclavas". Se trata de una pieza fundamental para comprender el carácter gradual de la abolición de la esclavitud y de la inclusión ciudadana de los afrodescendientes en el Río de la Plata. Sus veintidós artículos muestran que la consecución de la libertad de los hijos de esclavizadas no fue inmediata ni plena ya que fueron puestos en un régimen especial de minoridad que los dejó sujetos a los amos de sus madres y a controles policiales especiales.

\section{INDEX}

Keywords: Slaves, Freedmen, Patronage, Abolition, Río de la Plata

Palabras claves: Esclavos, Libertos, Patronato, Abolición

\section{AUTHOR}

\section{MAGDALENA CANDIOTI}

Consejo Nacional de Investigaciones Científicas y Técnicas - Instituto de Historia Argentina y Americana Dr. Emilio Ravignani - Universidad de Buenos Aires / Universidad Nacional del Litoral, Argentina

Correo electrónico: mcandioti@yahoo.com 